\title{
Nghệ thuật trong kiến trúc chùa Angkorajaborey của Phật giáo Khmer tại Trà Vinh
}

\section{Lưu Khánh Quang ${ }^{1}$}

${ }^{1}$ Khoa Kiến Trúc, Trường Đại Học Xây dựng Miền Tây

\section{TỪ KHOÁ}

Nghệ thuật trong kiến trúc

Chùa Khmer

Chùa Angkorajaborey

\section{KEYWORDS}

Artistic in architecture

Khmer pagoda

AngKorajaborey Pagoda

\begin{abstract}
TÓM TẮT
Tôn giáo chính của người Khmer Nam Bộ là đạo Phật nên ngôi chùa có vị trí rất quan trọng. Họ coi ngôi chùa là trung tâm sinh hoạt của cả cộng đồng, Chùa Khmer không chỉ là nơi hoạt động tín ngưỡng tôn giáo mà còn là nơi diễn ra các hoạt động truyền thống của người Khmer. Ngôi chùa với những lễ nghi cầu cúng đã góp phần hữu hiệu vào việc đẩy mạnh ảnh hưởng của Phật giáo vào đời sống văn hóa tinh thần, tâm linh, cách ăn mặc và lối sống của người Khmer.
\end{abstract}

\section{1. Đặt vấn đề}

Văn hóa của người Khmer là sự kết hợp hài hòa giữa văn hóa truyền thống với văn hóa Bà La Môn và Phật giáo Nam Tông. Chùa Angkorajaborey là ngôi chùa có lịch sử lâu đời ở Trà Vinh, tọa lạc trên khu đất khoảng 4 ha (Hecta) bao quanh là các cây cổ thụ và hồ nước. Tổng thể ngôi chùa bao gồm các hạng mục như: ngôi chánh điện là điện thờ chính; sala (nhà hội) là nơi tín đồ dâng cúng lễ và cũng là nơi dùng bữa vào dịp lễ của nhà sư cùng phật tử; trai đường (thọ trai) nơi các sư tập trung thực phẩm và dùng bữa sau khi khất thực; dãy nhà tăng (tăng xá), nơi ở các sư; nhà ở của các lục cả, lục nhì (trụ trì trưởng, phó); lớp học cho các sư cũng là trường học cho trẻ em ở phum, sóc; tháp cốt, tháp thiêu, nơi đựng tro hài cốt sau hỏa táng; cổng chính, tường rào và cuối cùng là miếu thờ Ông Tà (Neakta). Tuy nhiên trong nội dung nghiên cứu tác giả chỉ nghiên cứu về cổng và chính điện của ngôi chùa.

\section{Nội dung nghiên cứu}

2.1. Nghệ thuật trong cách thiết kế và trang trí cổng vào Chùa AngKorajaborey

Cổng chùa mang dáng dấp giống như cổng tam quan của người Việt, có kết cấu bằng bêtông cốt thép, được sơn màu vàng vì đây là màu chủ đạo của Phật giáo. Phía trên cổng vào được trang trí theo mô típ truyền thống khá đặc sắc với ba ngọn tháp kiểu Angkor. Với hai bên được đúc hình chằn Yeak và ở giữa là gương mặt của ReaHu hai tay cầm mặt trăng nuốt vào. Sử dụng hình tượng của chằn với mục đích khơi nguồn sáng tạo nghệ thuật của người Khmer.

Hình tượng chằn được thể hiện với khuôn mặt dữ tợn, mắt lồi lên, mày xếch, miệng rộng, mũi to, chằn được đặt trong chùa còn thể hiện cao tinh thần khoan dung và chính nghĩa của Phật giáo đã chiến thắng sự hung bạo.

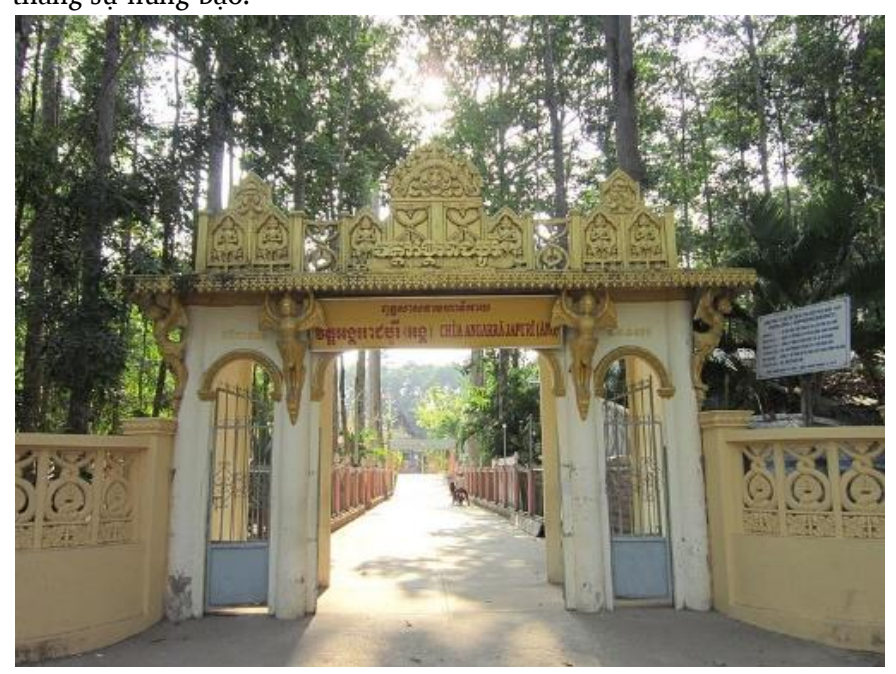

Hình 1. Cổng chùa AngKorajaborey [4].

Hình ảnh của Chằn thể hiện sự hung tợn và làm điều ác nhưng được đức Phật thuần phục và xin làm thần bảo vệ cho các ngôi chùa. Phía dưới ba ngọn tháp là các trụ cổng có các hình tiên nữ Kemnar và Krud, khi thiết kế thì hình ảnh dữ tợn của Chằn thì lúc nào cũng có sự 
xuất hiện của Krud tức là chim thần biểu hiện cho cái thiện dùng để khắc phục Chằn. Từ những hình tượng được trang trí ta thấy người Khmer đã tận dụng rất khéo léo các truyền thuyết, thần thoại, và văn hóa xưa vào kiến trúc để thể hiện tính tương phản đối lập nhau trong công trình kiến trúc là cái thiện và cái ác cùng tồn tại nhưng nó vẫn hòa quyện vào nhau không thể tách rời và trở thành một thể thống nhất. (Hình 1)

2.2. Nghệ thuật trong cách thiết kế và trang trí chính điện Chùa AngKorajaborey

Chính điện chùa AngKorajaborey hướng về hướng Đông, vì theo quan niệm của người dân Khmer thì đức Phật quay về hướng Đông để cứu thế, giúp con người thoát khỏi kiếp luân hồi. (Hình 2)

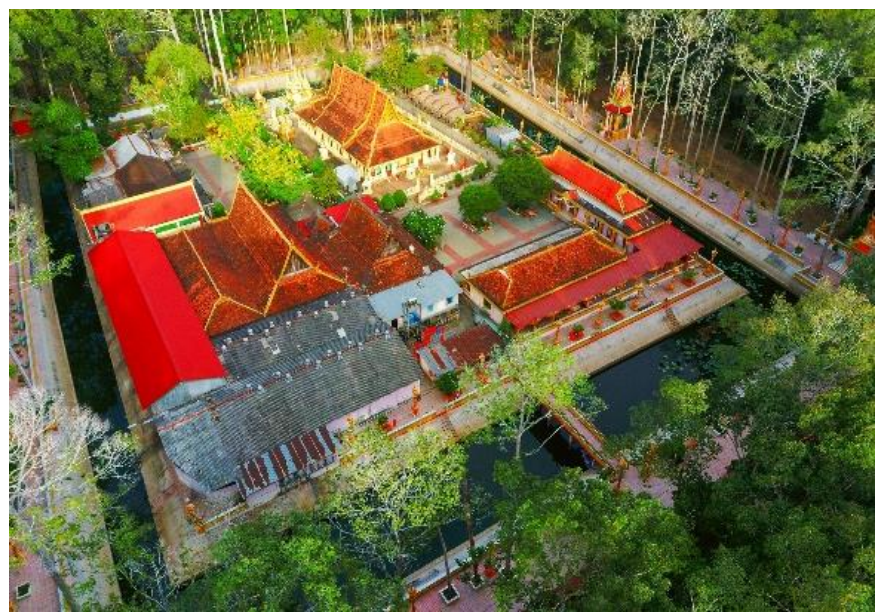

Hình 2. Tổng thể chùa AngKorajaborey [6].

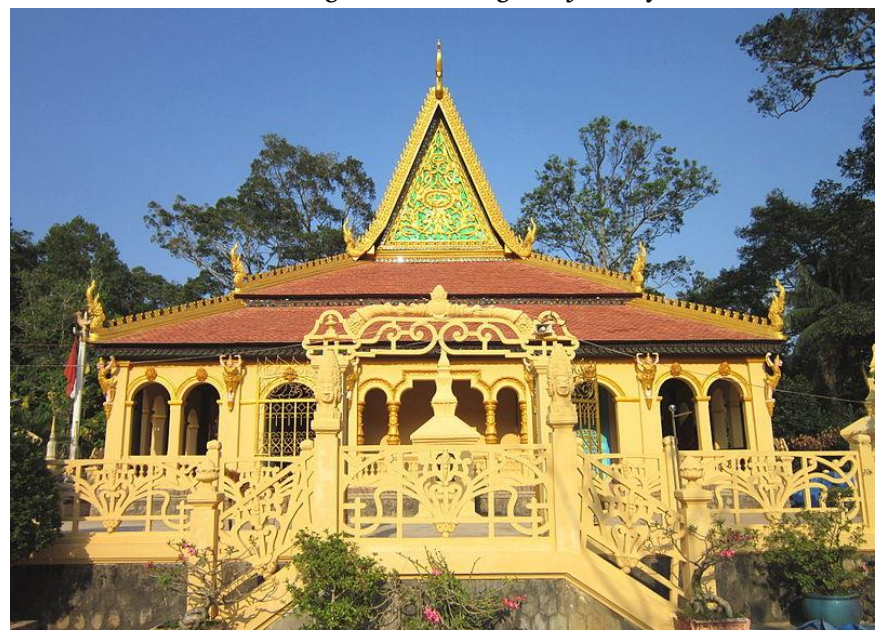

Hình 3. Chính điện chùa AngKorajaborey [4].

Chính điện của chùa được đặt trên nền cao $2 \mathrm{~m}$, xung quanh nền được thiết kế hàng trụ và lan can bao quanh chính điện tạo sự phân biệt rõ ràng với các khu chức năng khác trong tổng thể chùa.

Phần mái của chính điện được cấu tạo gồm ba cấp với độ dốc khác nhau nhằm làm giảm bớt đi sức nặng của mái thay vì để một khối thống nhất. Phần chóp mái trên cùng vươn lên cao hơn hai mái bên dưới thể hiện cho sự hài hòa vô tận giữa con người, tôn giáo và thiên nhiên bao la.

Phần mái trên cùng có hình tam giác cân lớn vì theo quan niệm của người Khmer thì tam giác là hình hoàn thiện nhất, tam giác còn thể hiện cái đẹp hoàn mỹ và tuyệt đối nhất, chính giữa hình tam giác cân được trang trí rất đặc sắc với nhiều hoa văn được lấy từ hình ảnh của nhiều nhánh cây đan xen vào nhau nhầm tránh sự khô cứng cho phần mái đồ sộ của công trình. (Hình 4)

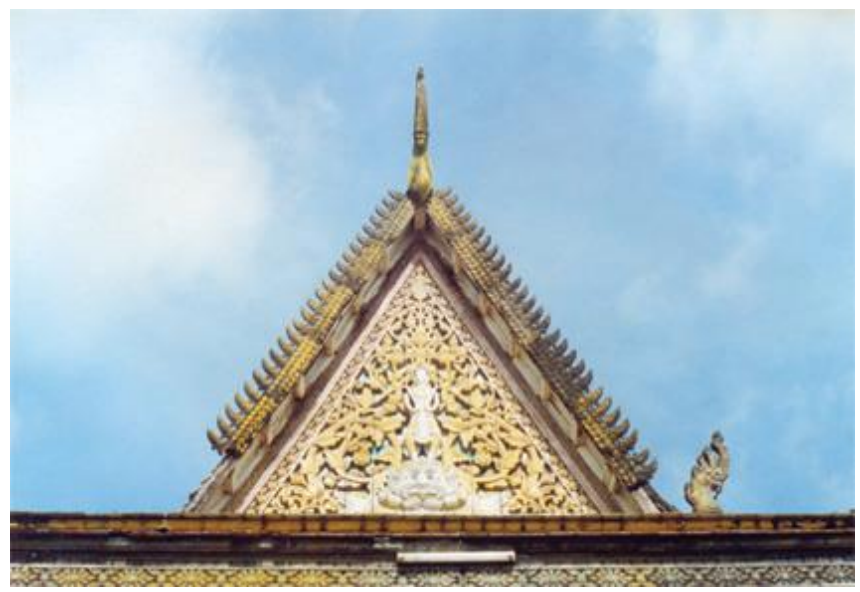

Hình 4. Hoa văn trang trí phần mái tam giác [3].

Các gò mái của chính điện còn được trang trí thần rắn Naga một nét rất đặc trưng của văn hóa người Khmer, đối với người Khmer thần rắn Naga biểu trưng cho sự thịnh vượng, là vị thần bảo vệ mùa màng mang nước tưới tắm cho ruộng vườn, mang nước đầy ấp cho các con sông. Hình ảnh thần rắn Naga với đuôi cong vút còn là biểu tượng cho sự kết nối của nhân gian với cõi niết bàn và tượng trưng cho sự dũng mãnh vĩnh cửu cho công trình.

Toàn bộ chính điện công trình được trụ bởi hệ thống 18 cột bằng gỗ quý. Hàng hiên chạy quanh chính điện dược thiết kế bởi các cột gỗ kết hợp với các mảng tường đặc rỗng che kín hành lang. (Hình 5)
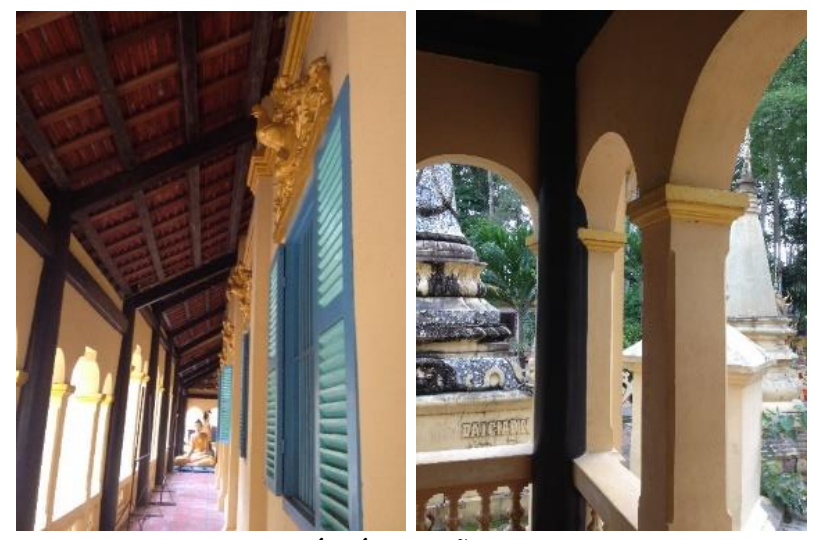

Hình 5. Kết cấu cột gỗ đỡ mái hiên. 


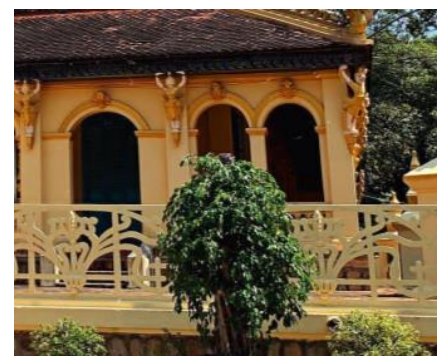

(a)

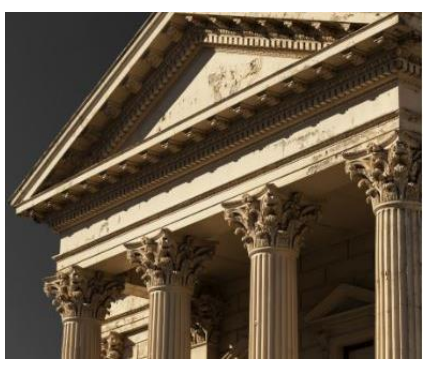

(b)
Hình 6. Hình thức trang trí đầu cột của người Khmer và Hy Lạp (cột Corinthian).

(a) Cột đỡ mái của người Khmer [6]

(b) Cột đỡ mái của người Hy Lạp [5]
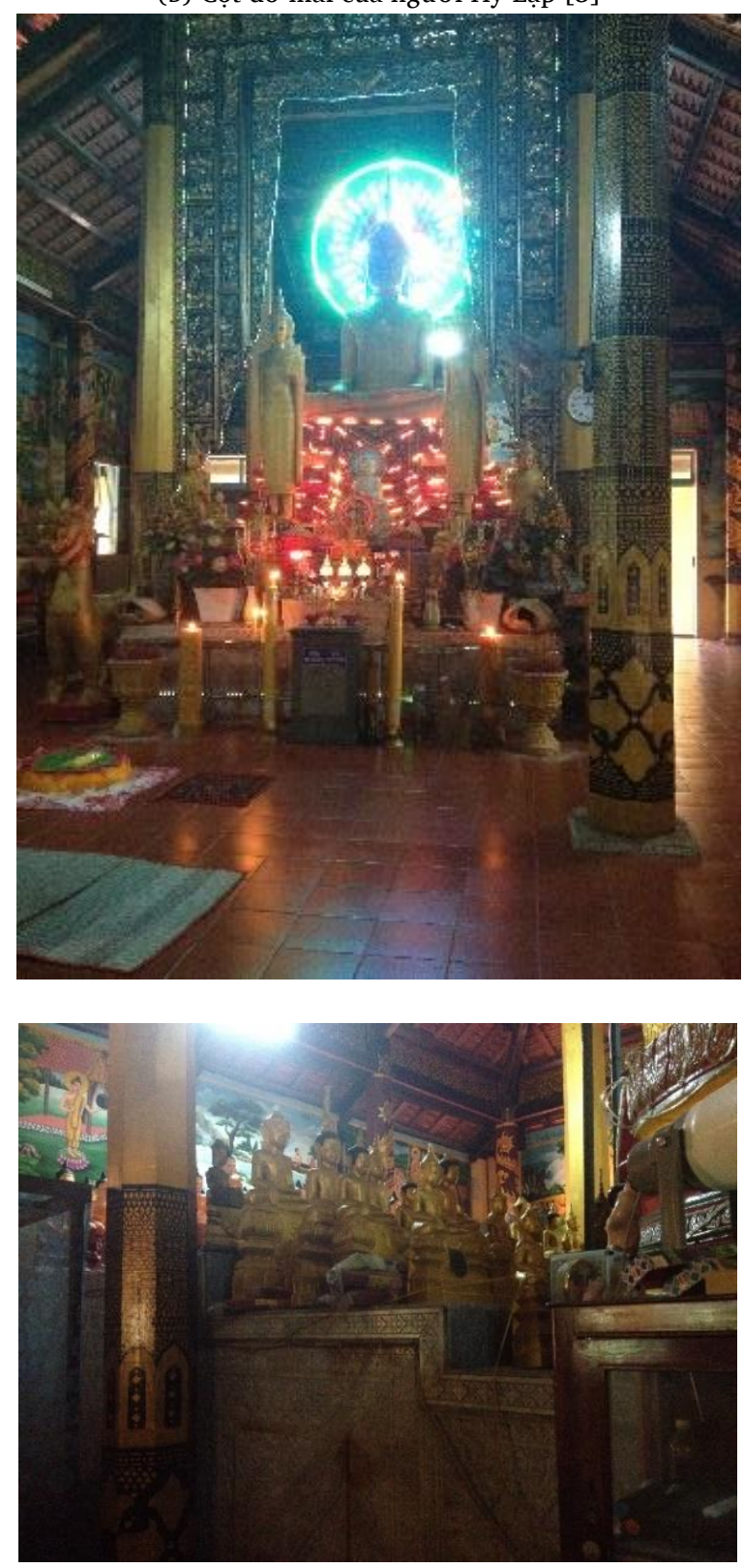

Hình 7. Phật thờ trong chính điện.
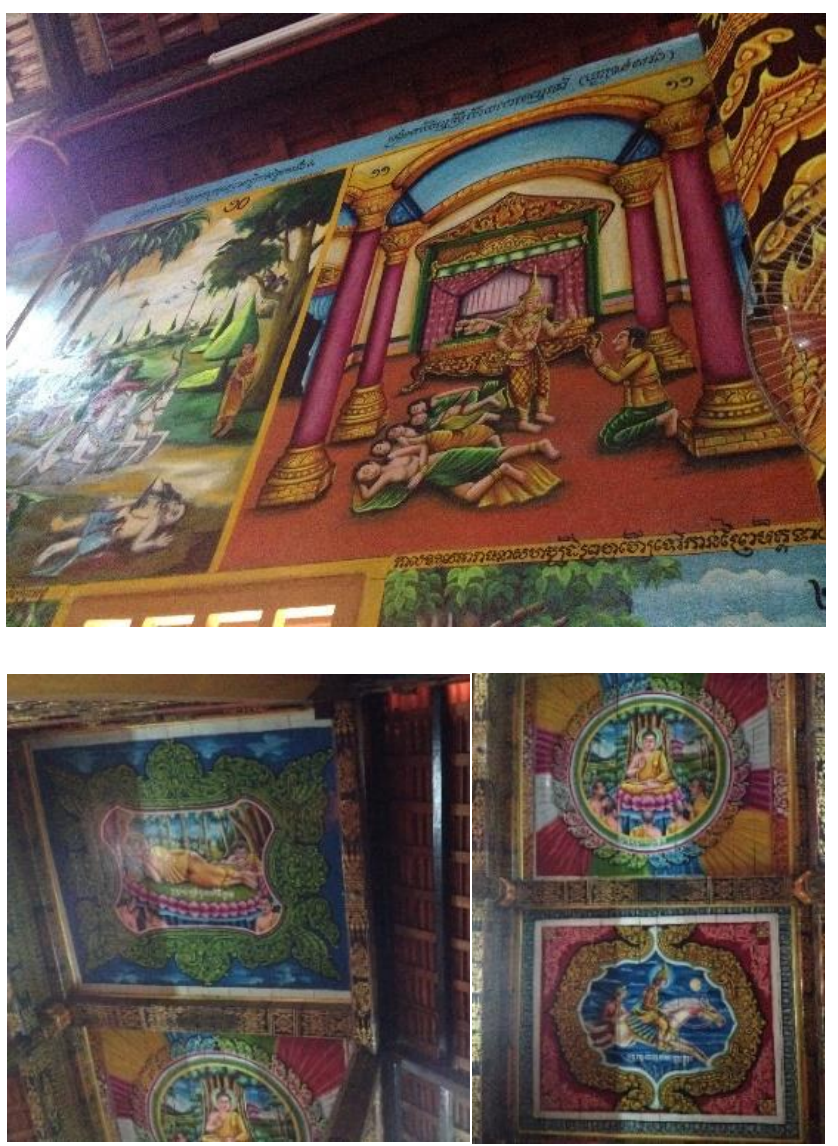

Hình 8. Tranh vẽ bên trong chính điện.

Hành lang phía trước chính điện bao gồm 6 cột, trong đó 4 cột giữa phần đầu cột được đúc hình tiên nữ Kemnar và phần đầu của 2 cột biên được đúc hình chim thần Krud mỏ ngậm viên ngọc, tất cả các tượng đúc đều đưa 2 tay lên để đỡ mái chùa giúp tăng thêm tính trang nghiêm và tạo sự vĩnh cửu cho công trình. Từ cách thức trang trí đầu cột của chùa ta thấy hình thức trang trí đầu cột của người Khmer có sự tương đồng với hình thức trang trí đầu cột của người Hy Lạp, tuy nhiên về hình tượng sử dụng trang trí thì hoàn toàn khác nhau, người Hy Lạp sử dụng hình ảnh hoa lá để trang trí cho đầu cột (cột Corinthian), người Khmer thì sử dụng hình ảnh các tượng tiên nữ và tượng thần Krud.

Từ những hình ảnh trên ta thấy người Khmer đã tận dụng tất cả các hình ảnh và biểu tượng trong truyền thuyết của dân tộc để trang trí cho ngôi chùa của họ, từ những hình ảnh này ta thấy được phần nào tâm tư tình cảm và nét văn hóa đặc sắc của người Khmer trong kiến trúc ngôi chùa.

Kết cấu chính điện là hỗn hợp gỗ, gạch và ngói. Hai hàng cột cái bằng gỗ quý cao vượt lên ở giữa tạo nên những bộ vì gồm hai kẻ hai bên, tất cả các lực đều được dồn lên nó sau đó áp vào các đầu cột đặt trên xà ngang nối giữa hai đầu cột cái tạo thành một bộ mái ở giữa chính điện cao vút tạo nên không khí trang nghiêm và linh thiêng khi bước vào bên trong. Bên trong chính điện ở giữa là bệ thờ Phật Thích Ca đây là nét đặc trưng của người Khmer. Với tượng Phật chính cao 
2,1 m và xung quanh còn có thêm khoảng 50 tượng Phật lớn nhỏ tạc bằng đá hoặc gỗ. (Hình 7)

Các mảng tường xung quanh chính điện được trang trí bởi những bức tranh vẽ kể về cuộc đời của Phật Thích Ca đặc biệt trên trần của chính điện là bốn bức bích họa lớn mô tả giai đoạn trong cuộc đời Đức Phật. Nội thất bên trong chính điện được chạm khắc rất tinh tế với 12 cột làm bằng gỗ quý sơn son thếp vàng hình rồng, các chi tiết được bố trí dày đặc nhưng vẫn thể hiện được yếu tố chính phụ và sự trang nghiêm của công trình. (Hình 8)

\section{Kết luận}

Chùa AngKorajaborey có sự cộng hưởng của nhiều chi tiết trang trí góp phần làm giảm sức nặng của ngôi chùa. Những nguyên tắc trang trí này đã ăn sâu vào trong tiềm thức của người Khmer và nghệ nhân, do đó ngôi chùa với nhiều lần trùng tu và sửa chữa nhưng vẫn không khác biệt với hình thức kiến trúc ban đầu. Tất cả các chi tiết trang trí từ các diềm mái, góc giữa mái, đầu cột, chân cột,... đều được khai thác một cách tỉ mỉ thông qua những hình ảnh điêu khắc gắn liền với văn hóa của người Khmer.

Thông qua kiến trúc ngôi chùa có thể nói lên được một phần nào đó tâm tư, tình cảm của người Khmer Nam Bộ. Nói chung, kiến trúc của chùa là một loại kiến trúc đơn giản nhưng vững chắc, tạo hiệu quả công năng cao đồng thời tất cả các thiết kế đều biến thành vật liệu cho trang trí làm cho công trình đặc sắc hơn. Chính vì vậy mà giữa kiến trúc và trang trí của người Khmer có quan hệ mật thiết với nhau, sự đơn giản hoá của kiến trúc được phối hợp với sự cầu kỳ và vô số những mô típ trang trí, điêu khắc để tạo ra một tổng thể hài hoà. Từ đó ta thây ngôi chùa của người Khmer là một tổng thể nghệ thuật kiến trúc và là đỉnh cao của thăng hoa tôn giáo, cái đẹp hiện ra trong sự thiêng liêng Phật giáo.

Từ đây chúng ta có thể thây ngôi chùa có ý nghĩa rất quan trọng trong đời sống tinh thần của người Khmer, là công trình mang tính văn hóa cụ thể và sâu sắc, công trình thể hiện tất cả bản chất và phong tục của người dân Khmer. Nên những giá trị trong thiết kế đó cần phải được bảo tồn và phát huy rộng rãi hơn trong giai đoạn hiện nay.

\section{Tài liệu tham khảo}

[1]. Nguyễn Khởi, Bảo tồn và trùng tu các di tích kiến trúc, NXB xây dựng, Hà Nội 2011.

[2]. Trần Ngọc Thêm, Cơ sở văn hóa Việt Nam, NXB giáo dục, 1999.

[3]. http://hcmufa.edu.vn/tap-chi/thong-tin-my-thuat-so-1-2/nghe-thuat-kientruc-trang-tri-chua-kh-mer-nam-bo-/

[4]. https://vi.wikipedia.org/wiki/Ch\%C3\%B9a_\%C3\%82ng

[5]. http://www.pictorem.com/8613/Old\%20Building\%20with\%20Corinthian\% 20Pillars\%2 0in\%20Portrait.html

[6]. https://thamhiemmekong.com/thong-tin-du-lich-mien-tay/chua-ang-ngoichua-khmer-co-tuyet-dep-o-tra-vinh.html 